\title{
Kernos
}

Revue internationale et pluridisciplinaire de religion grecque antique

9| 1996

Varia

\section{André MOTTE, Aspects du prophétisme grec}

\section{Pierre Somville}

\section{(2) OpenEdition \\ Journals}

\section{Édition électronique}

URL : http://journals.openedition.org/kernos/1206

DOI : 10.4000/kernos. 1206

ISSN : 2034-7871

Éditeur

Centre international d'étude de la religion grecque antique

Édition imprimée

Date de publication : 1 janvier 1996

ISSN : 0776-3824

\section{Référence électronique}

Pierre Somville, "André мотте, Aspects du prophétisme grec », Kernos [En ligne], 9 | 1996, mis en ligne le 16 juin 2011, consulté le 24 septembre 2020. URL : http://journals.openedition.org/kernos/1206 ; DOI : https://doi.org/10.4000/kernos.1206 
André Motre, Aspects du prophétisme grec, dans Prophéties et oracles, II : En Égypte et en Grèce, Paris, Cerf, 1994 (Supplément au Cabier Évangile, 89), p. 41-108.

Cette belle étude consacrée au prophétisme grec commence par un examen minutieux du vocabulaire, discernant soigneusement les fonctions du prophètès et du mantis : le premier parle pour le dieu, en tant qu'intermédiaire, tandis que l'autre est un « enthousiaste " plenus deo dont les actes rituels témoignent. Mais c'est surtout au prophètès que s'attache l'A., en distinguant successivement les aspects culturels, oraculaires et télestiques (c'est-à-dire liés à des initiations ou à des mystères). Des Hymnes homériques à Euripide, en passant par Platon et Bacchylide, les textes invoqués sont tous convaincants et clairement présentés, en grasses, entrecoupés de commentaires ad boc.

Après une substantielle introduction de quinze pages, composées sur deux colonnes chacune, l'A. examine successivement les croisements poétiques et philosophiques du prophétisme. De larges (et judicieux) extraits d'Hésiode et de Pindare illustrent le premier propos, tandis que les évocations de la geste et de l'œuvre de Pythagore, d'Héraclite et d'Empédocle achèvent l'examen comparatif annoncé. À mon avis, les pages consacrées au béotien Hésiode et à ses deux principales œuvres (la Théogonie et les Travaux) sont le véritable sommet de ce travail : c'est le moment planant où la protase va redescendre en apodose. C'est aussi le moment de la plus intense charge d'émotion religieuse que nous fait ressentir l'exégète, dont la plume, souvent sobre et réservée, se fait soudain entraînante et presque lyrique.

J'ajoute que cette étude, qui noue une série de thèmes, connus pour la plupart, est admirablement construite autour de l'enchaînement des textes antiques au moins autant que des notions lexicales. On croit parfois lire une sorte de préciseuse anthologie raisonnée. Chrestomathie, assurément, où l'honnête homme, comme le spécialiste, peut retrouver le fil d'or qui relie Homère et les Hymnes au Phèdre de Platon ou aux Bacchantes d'Euripide, sans oublier ceux que Mgr. Dies appelait si justement les philosophes anté-socratiques.

Maintenant, quelques broutilles... les quinze lignes consacrées à l'Ion de Platon (p. 55) pourraient parâttre courtes, vu l'importance du texte; la référence à Luc (I, 52) au titre de passage parallèle à la forme hésiodique « il ploie les superbes et exalte les humbles » devrait être complétée par une référence vétéro-testamentaire au livre de $\mathrm{Job}^{7}$; l'allusion occasionnelle à notre collègue et ami Suárez de la Torre à propos de Pindare aurait pu (ou dû) être assortie d'une référence à Jacqueline Duchemin. Enfin,

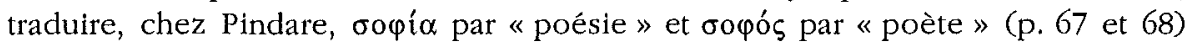
demandait au moins une justification.

Ces quelques brèves remarques n'entament évidemment en rien la grande qualité d'une contribution dont le mérite, à mes yeux, reste d'être tant pédagogique qu'anagogique, voire psychagogique, dans le sens le plus plein et le plus fort de ces trois termes.

Pierre SOMVILLE

(Université de Liège)

712,19 et 5,11, dans le commentaire obligé au Magnificat. Sans oublier VIRGILE, Énéide, VI, 853 : parcere subjectis et debellare superbos. 